\title{
Growth and Evaluation of Bulk GaN Crystals Grown on a Point Seed Crystal by Ba-Added Na Flux Method
}

\author{
Hiroki Imabayashi, Kosuke Murakami, Daisuke Matsuo, Yuma Todoroki, \\ Hideo Takazawa, Akira Kitamoto, Mihoko Maruyama, \\ Mamoru Imade*, Masashi Yoshimura and Yusuke Mori \\ Division of Electric, Electronic and Information Engineering, \\ Graduate School of Engineering, Osaka University \\ 2-1 Yamadaoka Suita-shi, Osaka 565-0871, Japan
}

(Received November 26, 2012; accepted February 12, 2013)

Key words: GaN wafer, bulk single crystal, crystal growth, point seed, Na flux method

We grew bulk gallium nitride ( $\mathrm{GaN}$ ) single crystals on a point seed by using the Baadded Na flux method and evaluated their structural and optical properties. As a result, we successfully grew habit-controlled single $\mathrm{GaN}$ crystals. The size of the largest crystal in this study was $7 \mathrm{~mm}$ along the [0001] direction and $9 \mathrm{~mm}$ along the $\langle 11-20\rangle$ direction after $200 \mathrm{~h}$ of growth. The cathodoluminescence (CL) images of (10-10) GaN wafers sliced from the grown crystal revealed that large areas of the wafer were dislocation free. Full widths at half maximum (FWHMs) of the X-ray rocking curve (XRC) of GaN (10-10) at low-dislocation-density sectors were from 32 to 61 arcsec. No green and yellow luminescence (GL and YL, respectively) peaks were detected from the room-temperature photoluminescence spectrum. From these results, it is found that the Ba-added $\mathrm{Na}$ flux method of GaN crystal growth on a point seed opens the possibility of fabricating highquality prismatic $\mathrm{GaN}$ bulk single crystals.

\section{Introduction}

Gallium nitride $(\mathrm{GaN})$ has attracted considerable attention for high-performance ultraviolet light-emitting diodes (LEDs), ${ }^{(1,2)}$ laser diodes (LDs), ${ }^{(3,4)}$ and high-power, highfrequency devices. ${ }^{(5)}$ Recently, GaN has also been expected for sensor materials such as ultraviolet sensors ${ }^{(6,7)}$ and high-temperature gas sensors ${ }^{(8,9)}$ because of its good sensitivity, recovery, and high durability. At present, sapphire and silicon are widely used as substrates of GaN-based devices because of their low cost and widespread availability. However, it is well known that the large lattice mismatch between a GaN-based epitaxial

${ }^{*}$ Corresponding author: e-mail: imade@eei.eng.osaka-u.ac.jp 
layer and a substrate leads to a high density of threading dislocations in epitaxial layers and the increase in reverse-bias leakage currents, which causes the decrease in the emission efficiency of LEDs ${ }^{(10)}$ and in this breakdown voltage, noise performance, and reliabilities of electronic devices ${ }^{(11)}$ and gas sensors. ${ }^{(12)}$

Using high-quality free-standing GaN wafers as a substrate is an effective method of improving the performance of $\mathrm{GaN}$-based devices. However, the present $\mathrm{GaN}$ wafers have a problem in the sense that they are more expensive than sapphire and silicon wafers. One of the valuable ways to mass produce and reduce the production cost of $\mathrm{GaN}$ wafers is to develop bulk growth with subsequent wafer slicing such as in the case of $\mathrm{Si}$. The hydride vapor phase epitaxy (HVPE) method, ${ }^{(13,14)}$ ammonothermal method, ${ }^{(15-17)}$ and $\mathrm{Na}$ flux method ${ }^{(18)}$ have been widely investigated to obtain bulk GaN single crystals. The free-standing GaN wafers commercially available now are fabricated by the HVPE method, which features fast growth but results in high dislocation density $\left(>10^{6} \mathrm{~cm}^{-2}\right)$. Among them, the Na flux method has the significant advantage of synthesizing highquality GaN crystals with low dislocation density. ${ }^{(19)}$ In a previous paper, we reported the Na-flux GaN grown on a newly developed seed called "GaN point seed". (20) The pyramidal crystal grown on a point seed had large dislocation-free areas and indicated high crystallinity. The problem of the point seed method is the shape of the grown crystal, which is pyramidal. The prismatic shape is ideal for producing a number of wafers. In addition, it is desirable to increase the size of the grown crystal as much as possible, because a number of large-diameter $\mathrm{GaN}$ wafers can be fabricated from grown crystals.

It is well known that small amounts of impurities in the solutions have dramatic effects on crystal growth. ${ }^{(21,22)}$ In the $\mathrm{Na}$ flux method, marked effects such as the suppression of the unfavorable formation of polycrystals on the crucible wall and changing crystal habit to prismatic could be found by the addition of a small amount of graphite and strontium, respectively. ${ }^{(18,23)}$ In a previous paper, it was reported that the Baadded Na flux method had several advantages of growing high-crystallinity (full widths at half maximum (FWHMs) of the X-ray rocking curve (XRC) for the $\{10-10\}$ faces was in the range from 33 to $120 \mathrm{arcsec}$ ) and low-Ba-contamination (Ba concentration in the crystals was below the detection limit, measured by secondary ion mass spectrometry (SIMS)) small prismatic crystals on the crucible wall. ${ }^{(24)}$

In this study, we tried to obtain prismatic bulk single crystals on a GaN point seed by the Ba-added Na flux method. Then, we report the structural and optical properties of the crystals to indicate the quality of the bulk GaN single crystal grown on the point seed by the Ba-added $\mathrm{Na}$ flux method in this paper.

\section{Experimental Procedure}

In an Ar-filled glove box, gallium, sodium metal, additives (carbon and barium), and a point seed were put in a ceramic crucible $(17 \mathrm{~mm}$ in inner diameter and $50 \mathrm{~mm}$ in height), and this crucible was enclosed in a stainless tube. The schematic illustration of the point seed is shown in Fig. 1. Details are found in ref. 20. The hole diameters of the mask were 1.2-1.6 mm. The Ga:Na mol ratios were 18:82 and 27:73. (Ga weights were 1.60 $\mathrm{g}$ for $\mathrm{Ga}: \mathrm{Na} 18: 82$ and $1.70 \mathrm{~g}$ for 27:73.) Graphite and barium contents relative to the 

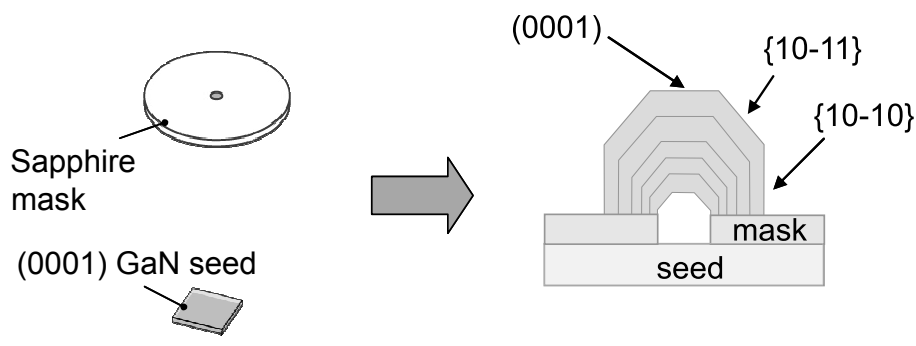

Fig. 1. Schematic of configuration and growth direction of GaN point seed. A GaN template was masked by mounting a sapphire plate with a small hole.

total $\mathrm{Ga} / \mathrm{Na}$ amount were fixed at 0.5 and $0.01 \mathrm{~mol} \%$, respectively. Graphite grains were added to prevent polycrystals from growing on the crucible wall. After taking the tube from the glove box, growth was conducted by the following procedure. First, the tube was connected to a $\mathrm{N}_{2}$ gas line, and heated to $850^{\circ} \mathrm{C}$ using an electric furnace. Then, the tube was maintained at $850^{\circ} \mathrm{C}$ and $4.0 \mathrm{MPa} \mathrm{N}_{2}$ gas for $48-300 \mathrm{~h}$. After the tube cooled naturally, the crucible was taken out from the tube. Residual $\mathrm{Na}$ and $\mathrm{Ga}-\mathrm{Na}$ alloy were removed from the crucible with ethanol and water.

The growth rate was calculated from the increase in the crystal size to investigate the dependence of the growth rate on the growth time. Because it was hard for us to check the size and weight of the growing crystal in situ, the dependence of growth time was investigated by evaluating the weight of the crystals grown for each predefined time. After slicing the crystal parallel to the (10-10) face and performing chemical mechanical polishing (CMP), the dislocation densities of the crystal were investigated by panchromatic cathodoluminescence (CL) measurements (Horiba, Imaging CL DF-100). The crystallinity was evaluated from the FWHM of the XRCs of GaN (10-10) with incident X-ray directions perpendicular $(\mathrm{c} \perp)$ and parallel $(\mathrm{c} / /)$ to the [0001] direction (Rigaku, Smart Lab-ES; Cu-Ka; $40 \mathrm{kV} ; 30 \mathrm{~mA}$ ). The optical properties of the crystal were evaluated on the basis of the PL spectra at room temperature. The excitation source of PL measurement was provided by a $325 \mathrm{~nm}$ He-Cd laser (Kommon IK3201R-F). PL detection was carried out using a cooled charge-coupled device (CCD, Horiba 1024× 256-OPEN-Synapse) in conjunction with a $32 \mathrm{~cm}$ monochromator (Horiba iHR320).

\section{Results and Discussion}

\subsection{Growth of GaN bulk single crystals by Ba-added Na flux method}

Figure 2 shows the relationship between growth time and weight of crystal grown in a Ba-added Na solution. The inset images were those of the crystals grown for 96 and 150 h. From Fig. 2, the crystal started to grow at $50 \mathrm{~h}$ after reaching the growth temperature. After $96 \mathrm{~h}$, the growth rate was significantly increased. The size of the crystal reached a $6 \mathrm{~mm}$ height, a $7 \mathrm{~mm}$ width, and a $1.8 \mathrm{~g}$ weight after $300 \mathrm{~h}$ of growth (a photograph of the crystal is shown in Fig. 3(a)). After $300 \mathrm{~h}$ of growth, the Ga source in the solution was depleted and the growth rate became close to zero. 


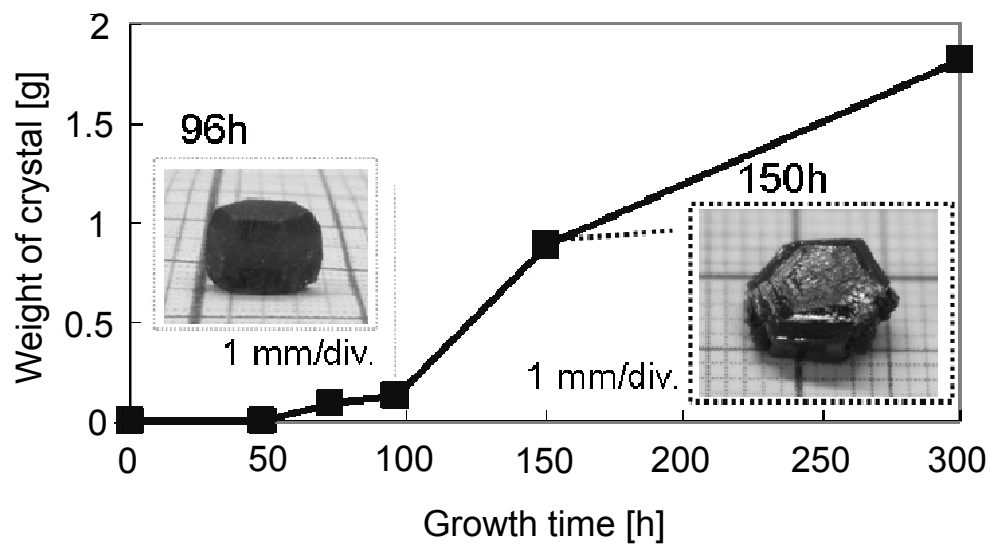

Fig. 2. Relationship between growth crystal and weight of grown crystal with Ba-added Na flux. The inset shows the single crystal grown with Ba-added Na flux for 96 (left) and $150 \mathrm{~h}$ (right).

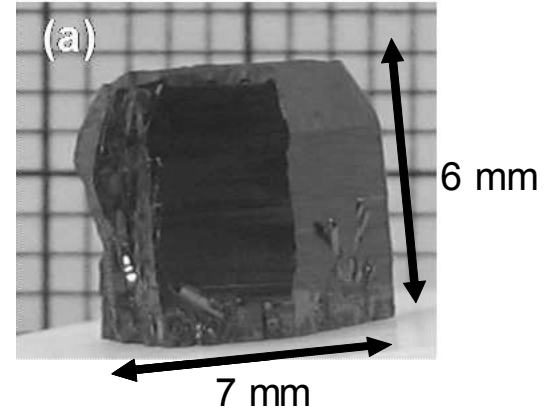

(c)

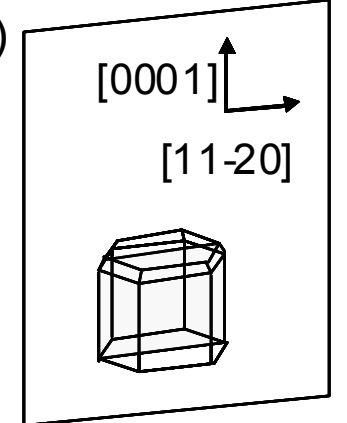

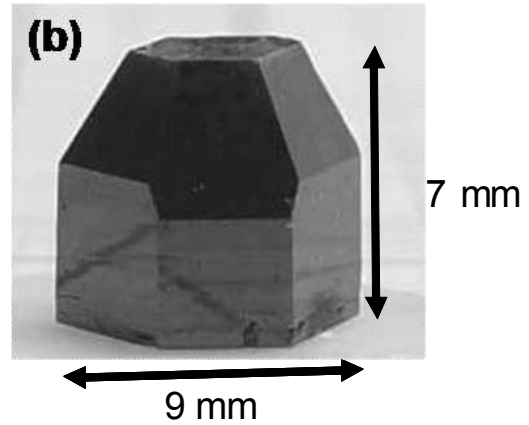

(d)

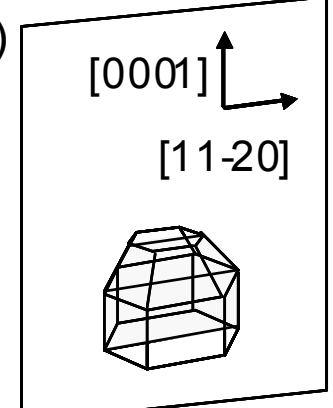

Fig. 3. Prismatic GaN single crystal grown by Ba-added Na flux method (a) with Gal $8 \mathrm{~mol} \% \mathrm{Na}$ flux for $300 \mathrm{~h}$ and (b) with Ga $27 \mathrm{~mol} \%$ for $200 \mathrm{~h}$. 
The apparent reason why the crystal growth started about $50 \mathrm{~h}$ after reaching the growth temperature is that it takes a long time for $\mathrm{N}$ species supplied from the gas phase to the flux close to the gas-liquid interface to reach the seed surface because the seed $\mathrm{GaN}$ was in the hole of the sapphire mask placed at the bottom of the crucible. The increase in the growth rate with increasing growth period was also observed in a previous study. ${ }^{(20)}$ In our previous paper, the increase in the growth rate was also caused by a decrease in the Ga ratio in the Ga-Na mixed solution. ${ }^{(25,26)}$

Then, we tried to grow a larger crystal by increasing the Ga content in the flux to $1.7 \mathrm{~g}$ to avoid the depletion of the Ga source. Ga:Na was changed to 27:73 to keep the flux depth constant. Figure 3(b) shows the photograph of the crystal grown with Ga 27 mol\% Na flux for $200 \mathrm{~h}$. The size of this crystal reached a $7 \mathrm{~mm}$ height, a $9 \mathrm{~mm}$ width, and over $1.9 \mathrm{~g}$ weight; this is larger than that grown for $300 \mathrm{~h}$ in $\mathrm{Ga} 18 \mathrm{~mol} \% \mathrm{Na}$ flux. In this case, most of the Ga source was also consumed during crystal growth. The growth rate along the [0001] direction was as high as that reported in a previous paper.(25) In this work, the size of the grown crystal was larger in the case of Ga $27 \mathrm{~mol} \%$ than in the case of Ga $18 \mathrm{~mol} \%$, which contradicts the result shown in ref. 22. We think that the size of the crystals grown in this study was restricted by the amount of Ga in the crucible because most of the Ga source was also consumed during long-time (over $200 \mathrm{~h}$ ) crystal growth. In other words, the real growth rates under this condition could be faster than the estimated ones. These results indicated that the Ba-added $\mathrm{Na}$ flux method opens the possibility of growing bulk GaN single crystals without decreasing the growth rate.

\subsection{Evaluation of structural and optical caracteristics of GaN crystal grown on point seed}

\subsubsection{CL measurement}

After slicing the crystals parallel to the (10-10) face and performing CMP, we evaluated the dislocation densities of the crystal from CL mapping images. The CL mapping image of the (10-10) face is shown in Fig. 4(a). Three types of striations, parallel to (0001), $\{10-11\}$, and $\{10-10\}$, were observed in Fig. 4(a). It was considered that these sectors were grown in different growth directions: [0001], $\langle 10-11\rangle$, and $\langle 10-10\rangle$, respectively (shown in Fig. 4(b)). Although similar sectors were also confirmed from the CL image of the typical GaN crystal grown on a point seed, ${ }^{(20)}$ the $\langle 10-10\rangle$ sector was widely developed only in the crystal grown by the Ba-added $\mathrm{Na}$ flux method. Figures 4(c), 4(d), and 4(e) show the high-magnification images of [0001], $\langle 10-11\rangle$, and $\langle 10-10\rangle$ growth sectors, respectively. No skeletal area was observed in the $\langle 10-11\rangle$ and $\langle 10-10\rangle$ sectors. In these sectors, no dark spots due to dislocation were observed in $336 \mu \mathrm{m} \times 336 \mu \mathrm{m}$ area over the large area of the crystal, corresponding to the dislocation density of less than $10^{3} \mathrm{~cm}^{-2}$. From this result, it is indicated that no negative effects such as increasing dislocation density are induced by the addition of $\mathrm{Ba}$.

The striation in the [0001] growth sector showed crooked lines, which was thought to be caused by skeletalization. This was consistent with the surface morphology of (0001) faces. On the other hand, straight striations parallel to $\{10-11\}$ and $\{10-10\}$ faces were observed in the $\langle 10-11\rangle$ and $\langle 10-10\rangle$ growth sectors, respectively. In the [0001] sector, the morphological instability may be due to nonuniform supersaturation over the 

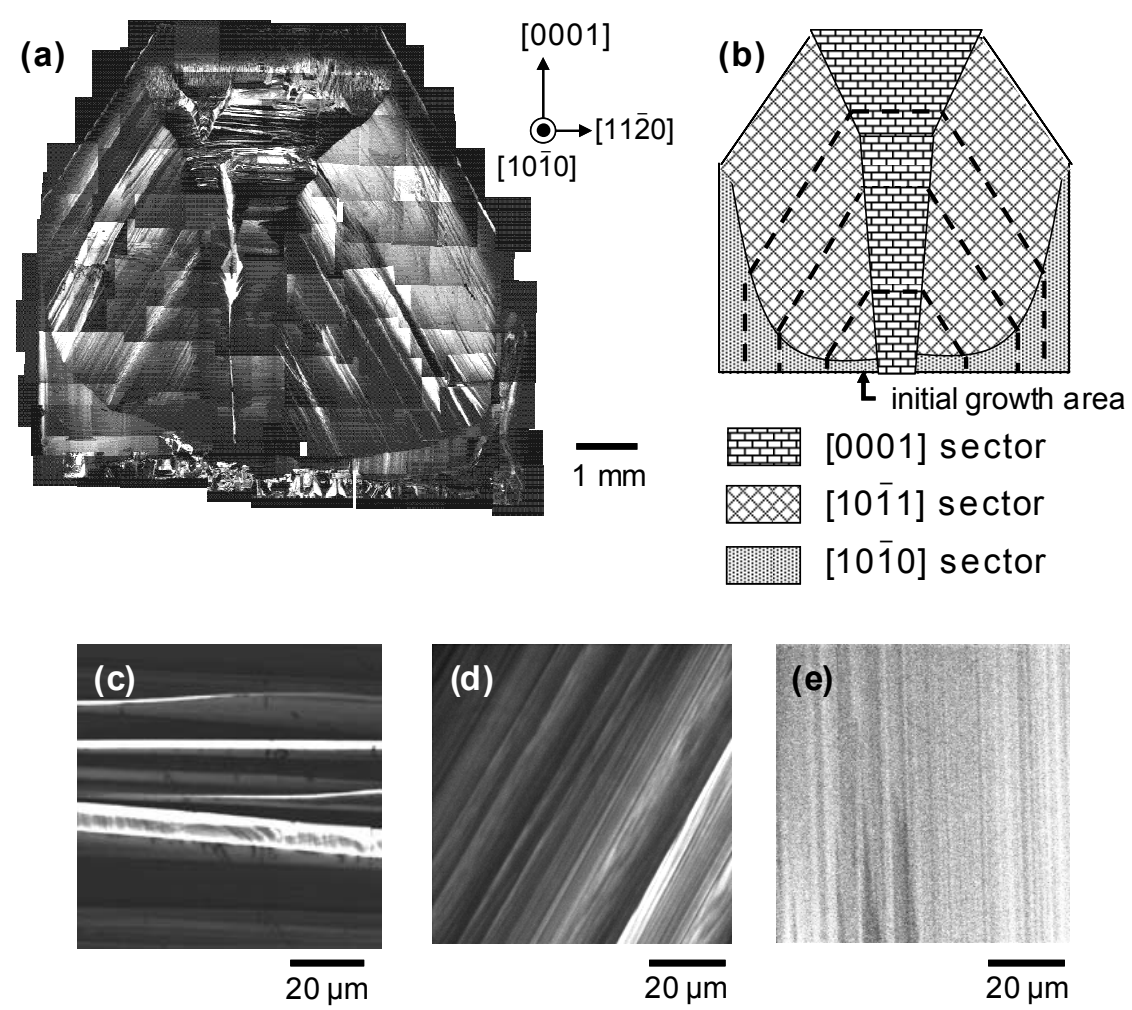

Fig. 4. (a) CL mapping image of $\mathrm{GaN}$ (10-10), (b)-(d) extended figures for [10-10], [10-11], and [0001] growth sectors, respectively.

seed surface. This is known as the Berg effect, which is produced by the preferential growth of the edges and corners of the crystal. This phenomenon produces a high supersaturation at the edge of a finite crystal.

From the CL measurement, it was found that the dislocation density in the growth sector without skeletal formation was very low, indicating that the GaN crystal with the low dislocation density could be realized by suppressing skeletal growth.

\subsubsection{XRC measurement}

Figure 5 shows the XRC profiles of $\mathrm{GaN}(10-10)$. The XRC profiles for the $\langle 10-11\rangle$ sector, as shown in Fig. 5(c), exhibited a single peak, indicating that it consisted of a single domain. Furthermore, FWHMs for $\mathrm{c} \perp$ and $\mathrm{c} / /$ were as narrow as 61 and 32 arcsec, respectively. The [0001] sector also showed the low FWHM (65 $\operatorname{arcsec}$ for $\mathrm{c} \perp$ and 53 $\operatorname{arcsec}$ for $\mathrm{c} / /$ ).

Compared with these XRCs, FWHMs for $\mathrm{c} \perp$ were larger than those for $\mathrm{c} / /$. Moreover, XRC for the X-ray incident beam perpendicular to the [0001] direction $(\mathrm{c} \perp$ ) of the initial growth stage, which correlates with the twist for the [0001] direction of the 

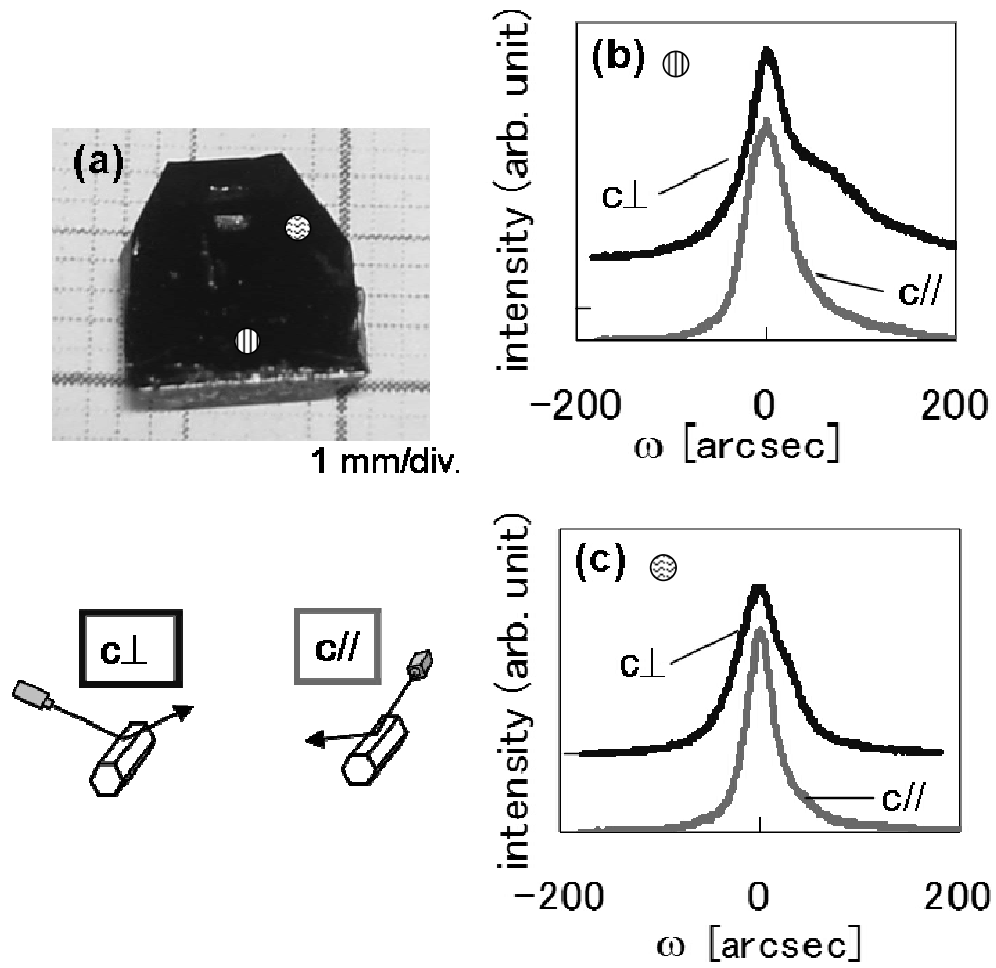

Fig. 5. (a) Photograph of GaN (10-10) of the crystal grown on point seed, and XRCs at (b) initial and (c) growth sectors.

GaN crystal, had the shoulder, and this shoulder almost disappeared in the XRC of the initial growth stage. This means that the strain between $\mathrm{GaN}$ and the sapphire substrate, which remains in the initial growth stage, is relaxed as the growth proceeded. In the $\mathrm{Na}$ flux method, it is known that the dislocation density, which has a relationship with the amount of strain, decreases during the crystal growth. ${ }^{(19)}$ From these results, the XRCs for the latter growth sector indicated that the GaN crystal grown on the point seed had high crystallinity, especially in this sector.

\subsubsection{PL measurement}

Figure 6 shows the PL spectra for the $\langle 10-11\rangle$ growth sector of the (10-10) $\mathrm{GaN}$ and typical (10-10) GaN samples grown by the HVPE method. Compared with the HVPE (10-10) GaN sample, the higher band-edge radiation and much lower green luminescence (GL: around $530 \mathrm{~nm}$ ) and yellow luminescence (YL: around $570 \mathrm{~nm}$ ) band radiation were detected from the bulk (10-10) GaN. In particular, no GL and YL band radiations, which slightly appeared in the room-temperature PL spectrum of a typical GaN crystal grown by the Na flux method, ${ }^{(27)}$ were confirmed in the spectrum of $\mathrm{GaN}$ grown by the Ba-added $\mathrm{Na}$ flux method. 


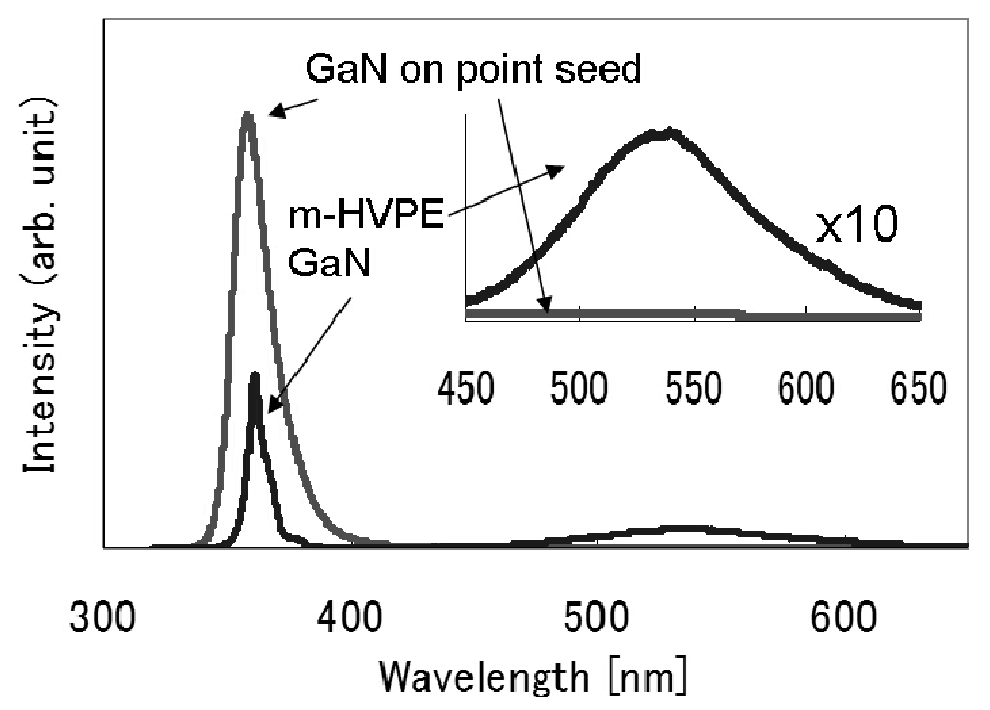

Fig. 6. PL spectra for (10-10) faces of bulk GaN grown on point seed and typical HVPE-GaN sample.

It is known that the PL intensity of the GaN crystal grown by the LPE method is much stronger at around $360 \mathrm{~nm}$ than that of the metal organic chemical vapor deposition (MOCVD)-GaN because the crystal quality of GaN grown by LPE was much greater than that of the MOCVD-GaN.(28) It was reported that the origins of the GL and YL bands for the GaN crystal were the Ga vacancy, ${ }^{(29)}$ incorporation of impurities such as $\mathrm{Li}^{(30)}$ and $\mathrm{Ca},{ }^{(24)}$ and the combination of $\mathrm{O}$ incorporation and $\mathrm{N}$ vacancy. ${ }^{(31)}$ We expected that the crystal grown on a point seed had few defects such as nonradiative centers and impurity incorporation. This result is consistent with the CL data for dislocation density, which is one of the origins of the nonradiative center. In this work, no detailed investigation of the relationship between impurities and PL spectra was conducted, and this will be investigated in a future paper.

\section{Summary}

In summary, we have achieved the growth of habit-controlled single GaN crystals on a point seed in a Ba-added Ga-Na solution. The maximum size of the crystal reached $7 \mathrm{~mm}$ in the [0001] direction and $9 \mathrm{~mm}$ in the $\langle 11-20\rangle$ direction after $200 \mathrm{~h}$ of growth. Panchromatic CL images showed that no dark spots were observed in large areas of the [10-11] and $\langle 10-10\rangle$ growth sectors, indicating that there were very few dislocations in the crystal. The FWHMs of GaN (10-10) XRC for the X-ray incident directions of $\mathrm{c} \perp$ and $\mathrm{c} / /$ were 61 and 32 arcsec, respectively, showing high crystallinity. High band-edge radiation and much lower GL and YL band radiations were detected from the (10-10) GaN. This data indicated that this crystal had very few defects and impurities. 


\section{References}

1 K. K. Chu, P. C. Chao, M. T. Pizzella, R. Actis, D. E. Meharry, K. B. Nichols, R. P. Vaudo, X. Xu, J. S. Flynn, J. Dion and G. R. Brandes: IEEE Electron Device Lett. 25 (2004) 596.

2 M. Kim, T. Fujita, S. Fukahori, T. Inazu, C. Pernot, Y. Nagasawa, A. Hirano, M. Ippommatsu, M. Iwaya, T. Takeuchi, S. Kamiyama, M. Yamaguchi, Y. Honda, H. Amano and I. Akasaki: Appl. Phys. Express 4 (2011) 092102.

3 Y. Enya, Y. Yoshizumi, T. Kyono, K. Akita, M. Ueno, M. Adachi, T. Sumitomo, S. Tokuyama, T. Ikegami, K. Katayama and T. Nakamura: Appl. Phys. Express 2 (2009) 082101.

4 D. Kasahara, D. Morita, T. Kosugi, K. Nakagawa, J. Kawamata, Y. Higuchi, H. Matsumura and T. Mukai: Appl. Phys. Express 4 (2011) 072103.

5 W. Saito, Y. Takada, M. Kuraguchi, K. Tsuda, I. Omura, Y. Ogura and H. Ohashi: IEEE Trans. Electron Devices 50 (2003) 2528.

6 K. S. Stevens, M. Kinniburgh and R. Beresford: Appl. Phys. Lett. 66 (1995) 3518.

7 C.-H. Chen, C.-M. Tsai, C.-F. Cheng, S. F. Yen, P.-Y. Su, Y. Tsai and C.-N. Tsai: Jpn. J. Appl. Phys. 51 (2012) 04DG15.

8 D.-S. Lee, J.-H. Lee, Y.-H. Lee and D.-D. Lee: Sens. Actuators, B 89 (2003) 305.

9 L. Voss, B. P. Gika and S. J. Pearton: J. Vac. Sci. Technol., B 23 (2005) 2373.

10 S.-N. Lee, H. S. Paek, J. K. Son, T. Sakong, E. Yoon, O. H. Nam and Y. Park: Physica, B 376 -377 (2006) 532.

11 J. W. P. Hsu, M. J. Manfra, R. J. Molnar, B. Heying and J. S. Speck: Appl. Phys. Lett. 81 (2002) 79.

12 T. Hashizume, M. Kaneko, J. Kotani, T. Kokawa, T. Kimura and T. Sato: IEIC Technical Report 106 (2006) 93.

13 H. P. Maruska and J. J. Tietjen, Appl. Phys. Lett. 15 (1969) 327.

14 K. Fujito, S. Kubo, H. Nagaoka, T. Mochizuki, H. Namita and S. Nagao: J. Cryst. Growth 311 (2009) 3011.

15 A. Yoshikawa, E. Ohshima, T. Fukuda, H. Tsuji and K. Oshima: J. Cryst. Growth 260 (2004) 67.

16 B. Wang, M. Callahan, K. Rakes, L. Bouthillette, S.-Q. Wang, D. Bliss and J. Kolis: J. Cryst. Growth 287 (2006) 376.

17 R. Dwillinski, R. Dradzinski, J. Grarczynski, L. P. Sierzputowski, A. Puchalski, Y. Kanbara, K. Yagi, H. Minakuchi and H. Hayashi: J. Cryst. Growth 311 (2009) 3015.

18 F. Kawamura, M. Morishita, M. Tanpo, M. Imade, M. Yoshimura, Y. Kitaoka, Y. Mori and T. Sasaki: J. Cryst. Growth 310 (2008) 3946.

19 F. Kawamura, M. Tampo, N. Miyoshi, M. Imade, M. Yoshimura, Y. Mori, Y. Kitaoka and T. Sasaki: J. Cryst. Growth 311 (2009) 3019.

20 M. Imade, K. Murakami, D. Matsuo, H. Imabayashi, H. Takazawa, Y. Todoroki, A. Kitamoto, M. Maruyama, M. Yoshimura and Y. Mori: Cryst. Growth Des. 12 (2012) 3799.

21 F. Kawamura, M. Kamei and I. Yasui: J. Am. Ceram. Soc. 82 (1999) 774.

22 F. Kawamura and I. Yasui: J. Am. Ceram. Soc. 84 (2001) 1341.

23 T. Iwahashi, Y. Kitaoka, M. Kawahara, F. Kawamura, M. Yoshimura, Y. Mori, T. Sasaki, R. Armitage and H. Hirayama: Jpn. J. Appl. Phys. 46 (2007) L103.

24 H. Ukegawa. Y. Konishi, T. Fujimori, N. Miyoshi, M. Imade, M. Yoshimura, Y. Kitaoka, T. Sasaki and Y. Mori: Proc. SPIE-Int. Soc. Opt. Eng. 7939 (2011) 79392A.

25 M. Imade, Y. Hirabayashi, Y. Konishi, H. Ukegawa, N. Miyoshi, M. Yoshimura, T. Sasaki, Y. Kitaoka and Y. Mori: Appl. Phys. Express 3 (2010) 075501.

26 M. Imade, Y. Hirabayashi, N. Miyoshi, M. Yoshimura, Y. Kitaoka, T. Sasaki and Y. Mori: Cryst. Growth Des. 11 (2011) 2346. 
27 K. Omae, T. Iwahashi, F. Kawamura, M. Yoshimura, Y. Mori and T. Sasaki: Jpn. J. Appl. Phys. 43 (2004) L173.

28 F. Kawamura, T. Iwahashi, K. Omae, M. Morishita, M. Yoshimura, Y. Mori and T. Sasaki: Jpn. J. Appl. Phys. 42 (2003) L4.

29 J. Neugebauer and C. G. Van de Walle: Appl. Phys. Lett. 69 (1996) 22.

30 M. Honjo, H. Imabayashi, H. Takazawa, Y. Todoroki, D. Matsuo, K. Murakami, M. Maruyama, M. Imade, M. Yoshimura, T. Sasaki and Y. Mori: Jpn. J. Appl. Phys. 51 (2012) 121002.

31 M. A. Reshchikov and H. Morkoc: J. Appl. Phys. 97 (2005) 61301.

\section{About the Authors}

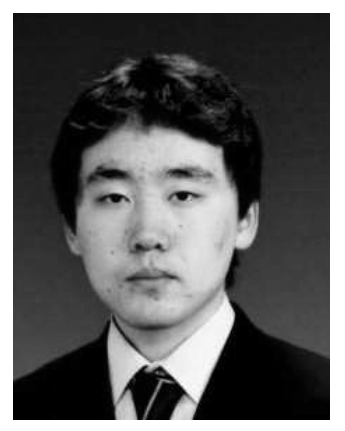

Hiroki Imabayashi received his B.S. degree in Applied Materials Science from Osaka Prefecture University, Sakai, Japan, in 2008 and M.S. degree in Chemistry from Kyoto University, Kyoto, Japan, in 2010. He is currently a graduate student of engineering, Osaka University, Suita, Japan. $\mathrm{He}$ is engaged in research on the growth of nitride crystals. $\mathrm{He}$ is a member of the Japan Society of Applied Physics and the Japanese Association for Crystal Growth.

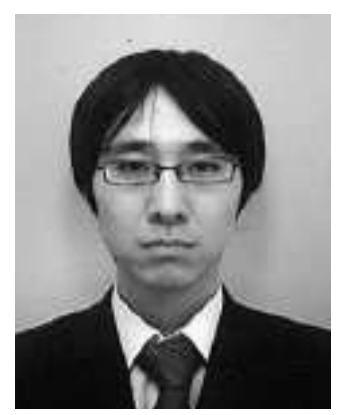

Kosuke Murakami received his B.S. and M.S. degrees in Physics from Aoyama Gakuin University, Sagamihara, Japan, in 2005 and 2007, respectively. He is currently a graduate student of engineering, Osaka University, Suita, Japan. He is engaged in research on the growth of nitride crystals. He is a member of the Japan Society of Applied Physics.

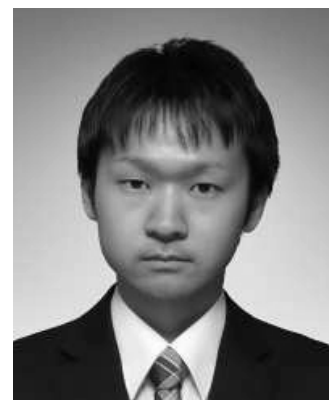

Daisuke Matsuo received his B.S., M.S., and Ph.D. degrees from the Department of Applied Chemistry of Okayama University of Science, Okayama, Japan, in 2006, 2008, and 2011, respectively. He is currently a researcher in the Division of Electrical, Electronic and Information Engineering, Osaka University. He is engaged in research on the growth of nitride crystals. 

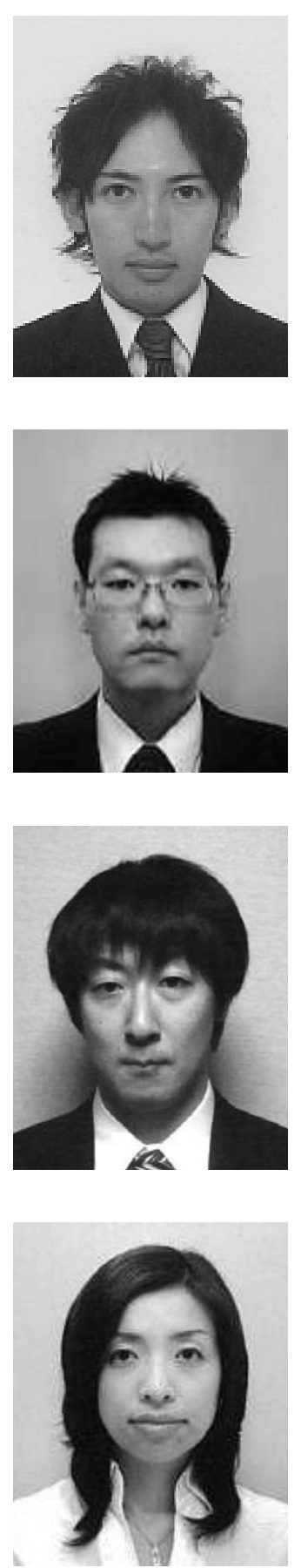

Yuma Todoroki received his B.S. and M.S. degrees in Environmental Chemistry from Miyazaki University, Miyazaki, Japan, in 2008 and 2010, respectively. He is currently a researcher in the Division of Electrical, Electronic and Information Engineering, Osaka University. He is engaged in research on the growth of nitride crystals.

Hideo Takazawa received his B.S. and M.S. degrees from the Department of Applied Chemistry of Kanagawa Institute of Technology, Atsugi, Japan, in 2001 and 2009, respectively. He is currently a researcher in the Division of Electrical, Electronic and Information Engineering, Osaka University. He is engaged in research on the growth of nitride crystals.

Akira Kitamoto received his B.S. and M.S. degrees in Chemistry from Kyushu University in 2008 and 2010, respectively. He is currently a researcher in the Division of Electrical, Electronic and Information Engineering, Osaka University. He is engaged in research on the growth of nitride crystals.

Mihoko Maruyama received her B.S., M.S., and Ph.D. degrees in Earth and Planetary Materials Science from Tohoku University, Sendai, Japan, in 2004, 2006, and 2009, respectively. She is currently a Project Assistant Professor in the Division of Electrical, Electronic and Information Engineering. Her research interests include crystal growth of gallium nitride and biomaterials. She is a member of the Japan Society of Applied Physics, the Japanese Association for Crystal Growth, and the Japan Society of Microgravity Application. 

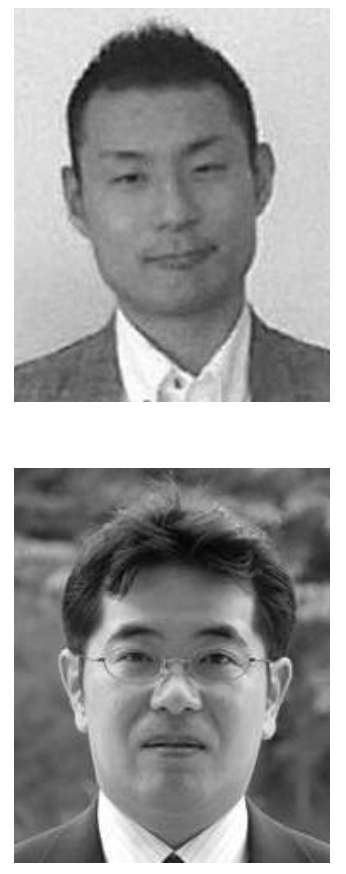

Mamoru Imade received his B.S., M.S., and Ph.D. degrees in Electrical Engineering from Osaka University, Suita, Japan, in 2003, 2004, and 2007, respectively. $\mathrm{He}$ is currently an Assistant Professor in the Division of Electrical, Electronic and Information Engineering. His research interests include crystal growth of gallium nitride and silicon carbide. He is a member of the Japan Society of Applied Physics and the Japanese Association for Crystal Growth.

Masashi Yoshimura received his B.S., M.S., and Ph.D. degrees in Electrical Engineering from Osaka University, Suita, Japan, in 1994, 1996, and 1999, respectively. He worked as an Assistant Professor from 1999 to 2007, and is currently an Associate Professor in the Division of Electrical, Electronic and Information Engineering. His research interests include crystal growth of functional materials and nonlinear optical crystals. Dr. Yoshimura is a member of the Optical Society (OSA), the Japan Society of Applied Physics, the Laser Society of Japan, and the Japanese Association for Crystal Growth. He received the Commendation for Science and Technology from the Minister of Education, Culture, Sports, Science and Technology in the Research Category in 2007, the German Innovation Award, Gottfried Wagener Prize, in 2012, and so on.

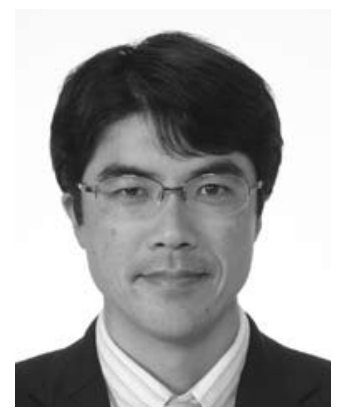

Yusuke Mori received his B.S., M.S., and Ph.D. degrees in electrical engineering from Osaka University, Suita, Japan, in 1989, 1991, and 1996, respectively. He worked as an Assistant Professor from 1993 to 1999, a Lecturer from 1999 to 2000, an Associate Professor from 2000 to 2007, and is currently a Professor in the Division of Electrical, Electronic and Information Engineering. His research interests include crystal growth of nonlinear optical crystals for ultraviolet light generation and $\mathrm{THz}$ wave generation, protein, and gallium nitride. He is a Representative Director of SOSHO, Inc. since 2005. He is a member of the Japan Society of Applied Physics, the Laser Society of Japan, and the Japanese Association for Crystal Growth. He received the Commendation for Science and Technology from the Minister of Education, Culture, Sports, Science and Technology in the Research Category in 2007 and 2008, the German Innovation Award, Gottfried Wagener Prize, in 2012, and so on. 